\title{
Correction to: Retrobulbar tube shunt: anterior chamber to back of the eye (A2B) efficacy in glaucomatous eyes with uncontrolled IOP
}

\author{
Mario Montelongo ${ }^{1}$ - Francesc March de Ribot ${ }^{2} \cdot$ Earl Randy Craven $^{3} \cdot$ William Eric Sponsel ${ }^{1,4,5}$ \\ Published online: 5 February 2021 \\ (C) Springer-Verlag GmbH Germany, part of Springer Nature 2021
}

\section{Correction to: Graefe's Archive for Clinical and Experimental Ophthalmology https://doi.org/10.1007/s00417-020-05006-x}

The published online version contains an error of the below reference. The published information is correct but not in the Pubmed inscription. See below.

Montelongo M, March de Ribot F, Craven ER, Sponsel WE. Retrobulbar tube shunt: anterior chamber to back of the eye (A2B) efficacy in glaucomatous eyes with uncontrolled IOP. Graefes Arch Clin Exp Ophthalmol. 2020 Nov 11.

instead of

Montelongo M, de Ribot FM, Craven ER, Sponsel WE. Retrobulbar tube shunt: anterior chamber to back of the eye (A2B) efficacy in glaucomatous eyes with uncontrolled IOP. Graefes Arch Clin Exp Ophthalmol. 2020 Nov 11.

The online version of the original article can be found at https://doi.org/ 10.1007/s00417-020-05006-x

Mario Montelongo

Mario-Montelongo@outlook.com

1 WESMDPA Baptist Medical Center, Glaucoma Service, Suite 306, 311 Camden Street, San Antonio, TX 78251, USA

2 Barcelona University Hospital, Barcelona, Catalonia, Spain

3 Wilmer Eye Institute, Johns Hopkins University, Bethesda, MD, USA

4 Vision Sciences, University of the IncarnateWord, San Antonio, TX, USA

5 Biomedical Engineering, University of Texas San Antonio, San Antonio, TX, USA 